
LA.UR-92. $92-754$

LA-UR--92-754

DE92 011286

Los Alamos National Laboatory is operated by the University of Calitornia tor the United States Deparment of Energy under contrae N.idns EN: :S

\title{
TITLE: THE LOS ALAMOS POP PROJECT: FEL OSCILLATOR EXPERIMENTS IN THE ULTRAVIOLET AND BEYOND
}

\author{
AUTHOR(S): Brian E. Newnam \\ Roger W. Warren \\ John C. Goldstein \\ Mark J. Schmitt \\ Steven $C$. Bender \\ Bruce E. Carloten \\ Donald $w$. Feldman \\ Fatrick C. O'Shea
}

SUEMITTED TO: Nuclear Instruments and Methods in Physics Research, proceedings of 1991 FEL Conference

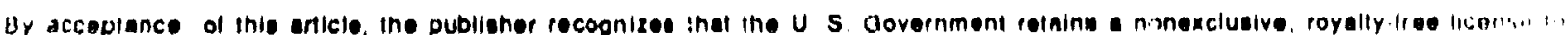
publish of ceproduce ine publioned lorm of this combribution or in allow othere lo do so, lor Government purposes

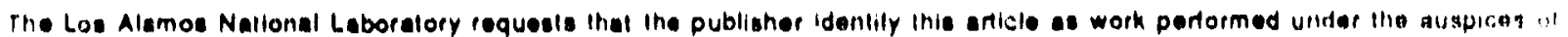
ithe U. S Dapartment of Energy.
}

\section{(1) A $A$ (O) Los Alamos Natlonal Laboratory (C) (3) indisitis




\section{DISCLAIMER}

This report was prepared as an account of work sponsured by an agency of the l/nited States (iovernment. Nelther the Inited States (iovernment nor any agency thereof, nor any of their empluyees, makes any warranty, express or implied, or assumes any legal liability or responsi. bility for the accuracy. completeness, or usefulness of any information, oppatatus, product, or process disclosed, or represents that its use would not infringe privately owned rights. Reference herein to any specilic commercial proxluct, process, of service by trade name, trademark. manufacturer, or atherwise des nen necessarily constitute or imply us endorsement, recom. nendation, of lavoring by the l/nited States Government ur any agency thereof the vews and opinions of authors expressed herein do not necessarily state or teflest those of the Inited silates (jovernment or any agency thereof 


\section{THE LOS ALAMOS POP PROJECT: FEL OSCILLATOR EXPERIMENTS IN THE ULTRAVIOLET AND BEYOND*}

Brian E. NEWNAM, Roger W. WARREN, John C. GOLDSTEIN, Mark J. SCHMITT, Steven C. BENDER, Bruce E. CARLSTEN, Donald W. FELDMAN, and Patrick G. O'SHEA

Los Alamos National Laboratory, MS J564, Los Alamos, New Mexico 87545, USA

The Los Alamos POP Project will include a series of proof-ot-principle FEL oscillator experimonts in 1952 designed to extend FEL operation into the ultraviulet (UV) and vacuum ultraviolet (VUV). With beam energy extended to $50 \mathrm{MeV}$, enhanced beam brightness with a photoinjector, and appropriate UV and VUV ri sonator nptics, the Los Alamos FEL oscillator should have sufficient single-pass gain (:0-30\%) to reach below $200 \mathrm{~nm}$. The first goal will be lasing at $250 \mathrm{~nm}$ utilizing a permanent-magnet undulator with $5-\mathrm{mm}$ feriod or alternatively on the third harmonic with a $1-\mathrm{cm}$ period. To operate at VUV wavelengths of 200 and $150 \mathrm{~nm}$ (third harmonic), pulsed electromagnetic microwigglers with periods of $5.7-$ and $4.3 \mathrm{~mm}$ will be employed.

\section{Introduction}

The demand for tree-electron lasers (FELs) for scientific research and industrial processing will dramatically increase when the operating wavelength is extended into the VUV (100-200 nin) and XUV (10-100 nm) regions [1-5]. Up to this time, the shortest operating wavelength for any FEL oscillator is $240 \mathrm{~nm}$ using a storage ring [6], and at least two other storage-ring facilities are being constructed especially to reach below $100 \mathrm{~nm}[7,8]$. With the recent development of the laser photoinjector [9], rf-linacs are producing even brighter electron beams which may enable FELs evar.tually to operate down io $10 \mathrm{~nm}$. Additional advances: include high.precision magnetic wigglers [10] and multifacet resonator mirrors with useful reflectance down to $40 \mathrm{~nm}$ [11]. These developments inwirase the credibility of user facility proposals involving ${ }^{\prime}$ linacs $[12 \cdot 14]$.

-Thic work was supported by Los Alamos Exploratory Research and Development under the auspices of the U.S. Department of Energy. 
For an intermediate FEL extension into the VUV, Los Alamos scientists have designed a set of proof-of-principle (POP) FEL experiments using the existing APEX FEL oscillator. Over the last decade, this FEL has operated in the infrared from 3 to 45 $\mu \mathrm{m}$ [15-17]. To operate in the UV and VUV regions between 250 and $150 \mathrm{~nm}$, the $\mathrm{ff}$ linac energy will be raised above its nominal $40-\mathrm{MeV}$ design point (to $50 \mathrm{MeV}$ ) while using very short-period $(\leq 0.5 \mathrm{~cm})$ wigglers. The demonstrated capability of the laser photoinjector to produce a low emittance beam $(30 \pi \mathrm{mm}-\mathrm{mr}$, normalized, $90 \%$ of electrons) with $\geq 100$ A peak current [18] will be essential to the success of these experiments.

The first goal will be lasing at $250 \mathrm{~nm}$ utilizing a permanent-magnet undulator with 5-mm period (two-magnets per period), or alternatively on the third harmonic with a $1-\mathrm{cm}$ period. The feasibility of lasing on the third harmonic was demonstrated previously at $4 \mu \mathrm{m}$ with the Los Alamos FEL [19]. To operate at VUV wavelengths of 200 and $150 \mathrm{~nm}$ (third harmonic), pulsed electromagnetic (PEM) microwigglers $[20,21]$ with periods of 5.7- and $4.3 \mathrm{~mm}$ will be employed. (Evaluation of the practical utility of PEM wigglers will be one of the primary objectives of this project.) At $50 \mathrm{MeV}$, the electron beam brightness attainable wit a photoinjector should result in sufficient single-pass gain $(20-30 \%)$.

\section{Experimental apparatus and optical components}

The APEX FEL shown in Fig. 1 is based on a room-temperature, standing wave, 1.3.GHz if linac. During 1992, this FEL is scheduled to be used for experiments alternately at $\sim 3-\mu \mathrm{m}$ in the infrared as well as in the UVNUV. Thus, provisions are being made 10 have the respective resonator mirrors and magnetic undulators interchangeable and realigned in about one day. Wiih the linac operater at $50 \mathrm{MeV}$. Table 1 lists the operating parameters for 250,200 , and $150 \mathrm{~nm}$ neөdod to obtain respective single-pass optical gains of $33 \%, 33 \%$, and $20 \%$ as computed with the $3-D$ code FELEX [22]. Uniform-period undulator/wigglers are nevessary to maximize the gain, with the output power magnitude being a lesser priority. The parameters will be proportionatuly adjusted if the electron beam energy is less than $50 \mathrm{MeV}$. However, the normalized beam emittance must be close to that specified in Table $\mathrm{i}$. 
Multilayer dielectric mirrors with the cited reflectances are commercially produced for 193-nm and 248-nm excimer lasers by a number of coating companies using oxide layers such as $\mathrm{Al}_{2} \mathrm{O}_{3}$ and $\mathrm{SiO}_{2}$. For shorter wavelengths, fluoride multilayers are used by at least one commercial coater to produce $92-96 \%$ reflectance down to $146 \mathrm{~nm}$ [23].

A description of R. Warren's design of the slotted-tube, pulsed-electromagnet microwiggler is given in Ref. 21. Substantial effort is being given to providing a flat-top current pulse to the wiggler, since this determines the time-dependence of the wiggler magnetic field. Deviations from constant field during the 50- $\mu$ s electron macropulse will cause an undesirable variation of the FEL wavelength.

\section{Expected results}

The predicted optical performance of the Los Alamos APEX FEL at 250, 200, and $150 \mathrm{~nm}$ is summarized in Table 2. Sideband emission, to the extent it occurs at our relatively low gains, will augment the output energies and average powers. This was not included in the simulations. Predictions of single-pass gain versus internal peak power at the exit mirror, also obtained from FELEX simulations, are presented in Figs. 2 to 4. The predicted output powers listed in Table 2 were calculated from these curves at the intersection with the total loss lines. Megawatt peak powers are predicted at 250 and $200 \mathrm{~nm}$, but the power at $150 \mathrm{~nm}$ is expected to be substantially less due to lower gain and higher mirror losses.

\section{Summary}

The primary objective of the LOS Alamos UVIVUV POP project is to extend the operating range of FELs below $200 \mathrm{~nm}$. With the moderate electron energy available frcm the APEX.FEL of linac (40.50 MeV), attainment of adequate small-signal gain $(20-30 \%)$ on the third harmonic will require high-field, pulsed-electromagne! wigglers with periods of 4-6 mm and peak wiggler parameters of $\sim 1.4$. The bright electron beam available from the photoinjector will be essential at such low electron energies. Future upgrades of the linac energy to $260 \mathrm{MeV}$ are oxpected to provide a large gain enhancement for the $150-250-\mathrm{nm}$ range and permit lasing at wavelengths near $120 \mathrm{~nm}$. 


\section{References}

[1] B. E. Newnam, in Fre日-Electro > Lasers, Critical Reviews of Technology, SPIE Vol. 738, (1988) p. 155.

[2] Free-Electron Laser Applications in the Ultraviolet, OSA Tech. Digest Series, Vol. 4. D. A. G. Deacon and B. E. Newnam, Eds., (Optical Soc. Am., Washington. D.C.), Mar.,1988; also P. Morin, Synchrotron Radiation News 1 (1988) 11.

[3] D. A. G. Deacon and B. E. Newnam, J. Opt. Soc. Am.-B 6., 1061 (1989).

[4] B. E. Newnam, Opt. Eng. 30 (1991) 1100.

[5] C. Yamanaka, Nucl. Instr. and Meth. in Phys. Res., in these proceedings , 1992.

[6] G. N. Kulipanov, V. N. Litvinenko, I. V. Pinayev, V. M. Popik, A. N. Skrinskv, A. S. Sokolov, and N. A. Vinokurov, Nucl. Instr. and Meth. in Phys. Res. A296 (1991) 1.

[7] V. N. Litvinenko and J. M. J. Madey, in Free-Electron Laser and Synchrotron Source Technologies and Applications, Proc. SPIE Vol. 1552, (1992).

[8] D. Nolie, F. Brinker, M. Negrazus, D. Schirmer, and K. Wille, Nucl. Instr. and Meth. in Phys. Res. A296, (1990) 263.

[9] J. S. Fraser and R. L. Sheffield, IEEE J. Quantum Electron. QE.23. (1987) 1489.

[10] S. C. Gottschalk, D. C. Quimby, K. E. Robinson, and J. M. Slater, Nucl. Instr. and Meth. in Phys. Ros. A296. (1990) 579.

[11] M. L. Scott and B. E. Newnam, Optics News 15, (1989) 38.

[12] B. E. Newnam, at al., in Free-Electron Laser and Synchrotron Source Technologies and Applications, Proc. SPIE Vol. 1552. (1992).

[13] I. Ben-Zvi, L. F. Di Mauro, S. Krinsky, M. G. White, and L. H. Yu, Nucl. Instr. and Meth. in Phys. Res. A304, (1991) 181.

[14] G. R. Neil, J. J. Bisognano, D. Douglas, H. F. Dylla, G. A. Kraft, C. W. Leemann, P. Liger, D. V. Neutfer, C. K. Sinclair, and B. Yunn, Nucl. Instr. and Meth. in Phys. Res., in these proceedings, 1992.

[15] B. E. Newnam, R. W. Warren, R. L. Sheffleld, W. E. Stein, M. T. Lynch, J. S. Fraser, J. C. Goldstein, J. E. Sollid, T. A. Swann, J. M. Watson, and C. A. Brau, IEEE J, Quantum Electron. OE-21, (1985) 867.

[16] A. H. Lunıpkin, D. W. Foldman, J. E. Sollid, R. W. Warren, W. E. Stein, W. J. Johnson, J. M. Watson, B. E. Newnam, and J. C. Gcldstein, Nucl. Instr. and Meth. in Phys. Res. A296. (1990) 181. 
[17]P. G. O'Shea, S. C. Bender, B. E. Carlsten, J. W. Early, D. W. Feldman, R. B. Feldman, W. J. Johnson, A. H. Lumpkin, W. E. Stein, and T. J. Zaugg, Nucl. Instr. and Meth. in Phys. Res., in these proceedings, 1992.

[18] D. W. Feldman, S. C. Bender, B. E. Carlsten, J. Early, R. B. Feldman, W. J. D. Jchnson, A. H. Lumpkin, P. G. O'Shea, W. E. Stein, R. L. Sheffield, and K. McKenna, Nucl. Instr. and Meth. in Phys. Res. A304 (1991) 224.

[19]R. W. Warren, L. C. Haynes, D. W. Feldmian, W. E. Stein, and S. J. Gitomer, Nucl. Instr. and Meth. in Phys. Res. A296, (1990) 84.

[20] R. W. Warren, D. W. Feldman, and D. Preston, Nucl. Instr. and Meth. in Phys. Res. A296, (1990) 558.

[21] R. W. Warren, Nucl. Instr. and Meth. in Phys. Res., in there proceedings, 1992.

[22] B. D. M Vey, Nucl. Instr. and Meth. in Phys. Res. A250, (1986) 449.

[23] Acton Research Corp., Excimer \& UV Laser Optics. Product Catalog, p. 9. 
Table 1

FE! design parameters

\begin{tabular}{|c|c|c|c|}
\hline Wavelencth: & $250 \mathrm{~nm}$ & $200 \mathrm{~nm}$ & $150 \mathrm{~nm}$ \\
\hline \multicolumn{4}{|l|}{ Electron beam } \\
\hline Energy, MeV & 52 & 50 & 50 \\
\hline Energy spread, \% & 0.2 & 0.3 & 0.3 \\
\hline Peak current, A & 100 & 130 & 130 \\
\hline Micropulse FWHM, ps & 10 & 10 & 10 \\
\hline Micropulse rep. rate, $\mathrm{MHz}$ & 21.7 & 21.7 & 21.7 \\
\hline Charge/upulse, nC & 1 & 1 & 1 \\
\hline $\begin{array}{l}\text { Emittance, mm-mrad } \\
\text { (normalized, 90\%) }\end{array}$ & $30 \pi$ & $30 \pi$ & $30 \pi$ \\
\hline Macropulse duration, $\mu$ s & 50 & 50 & 50 \\
\hline Macropulse rep. rate, $\mathrm{Hz}$ & 1 & 1 & 1 \\
\hline \multicolumn{4}{|l|}{ Wiggler } \\
\hline Type & PM, 2 blk/per. & PEM & PEM \\
\hline Pericd, $\mathrm{mm}$ & 5.0 & 5.7 & 4.3 \\
\hline Gap, mm & 1 & 2 & 2 \\
\hline Peak field, Tesla & 0.6 & 2.6 & 3.5 \\
\hline K, peak & 0.3 & 1.4 & 1.4 \\
\hline No. Periods & 200 & 75 & 75 \\
\hline Lengrh, cm & 100 & 43 & 32 \\
\hline Magnet focus planes & 1 & 2 & 2 \\
\hline \multicolumn{4}{|l|}{ Optical Resonator } \\
\hline Length, m & 6.9 & 6.9 & 6.9 \\
\hline Mirror reflectance, \% & 99 & 97.5 & 94 \\
\hline
\end{tabular}


Table 2

Predicted optical performance of the Los Alamos APEX FEL in the UV and VUV

\begin{tabular}{lccc}
\hline Wavelength: & $250 \mathrm{~nm}$ & $200 \mathrm{~nm}$ & $150 \mathrm{~nm}$ \\
Optical harmonic & 1 & 3 & 3 \\
Small-signal gain, \% & 33 & 33 & 20 \\
$\begin{array}{l}\text { Internal peak power, MW } \\
\text { incident on exit mirror }\end{array}$ & 480 & 170 & 8 \\
$\begin{array}{l}\text { Output coupling, \% } \\
\text { per mirror (1-R-A) }\end{array}$ & 1 & 2 & 1 \\
$\begin{array}{l}\text { Peak output power, MW } \\
\text { Output energy, mJ } \\
50-\mu s \text { macropulse }\end{array}$ & 4.8 & 3.4 & 0.095 \\
$\begin{array}{l}\text { Average power, W } \\
50-\mu s \text { macropulse }\end{array}$ & 50 & 35 & 1 \\
$\begin{array}{l}\text { Average power, mW } \\
@ 1-H z \text { data acquisition rate }\end{array}$ & 1000 & 700 & 20 \\
\hline
\end{tabular}




\section{Flgure Captions}

Figure 1. Schematic of the I.os Alamos APEX FEL. At wavelengths below $200 \mathrm{~nm}$, it will be necessary to transport the output optical beam within a tube free of oxygen.

Figure 2. FEL optical gain at the fundamental harmonic at $250 \mathrm{~nm}$ as a function of internal peak power incident on the exit resonator mirror for APEX FEL design parameters given in Table 1 . The $3 \%$ cavity losses determine the internal power at saturation.

Figure 3. Same as Fig. 2, except 200-nm wavelength FEL oscillator.

Figure 4. Same as Fig. 2, except 150-nm wave :ength FEL oscillator. 


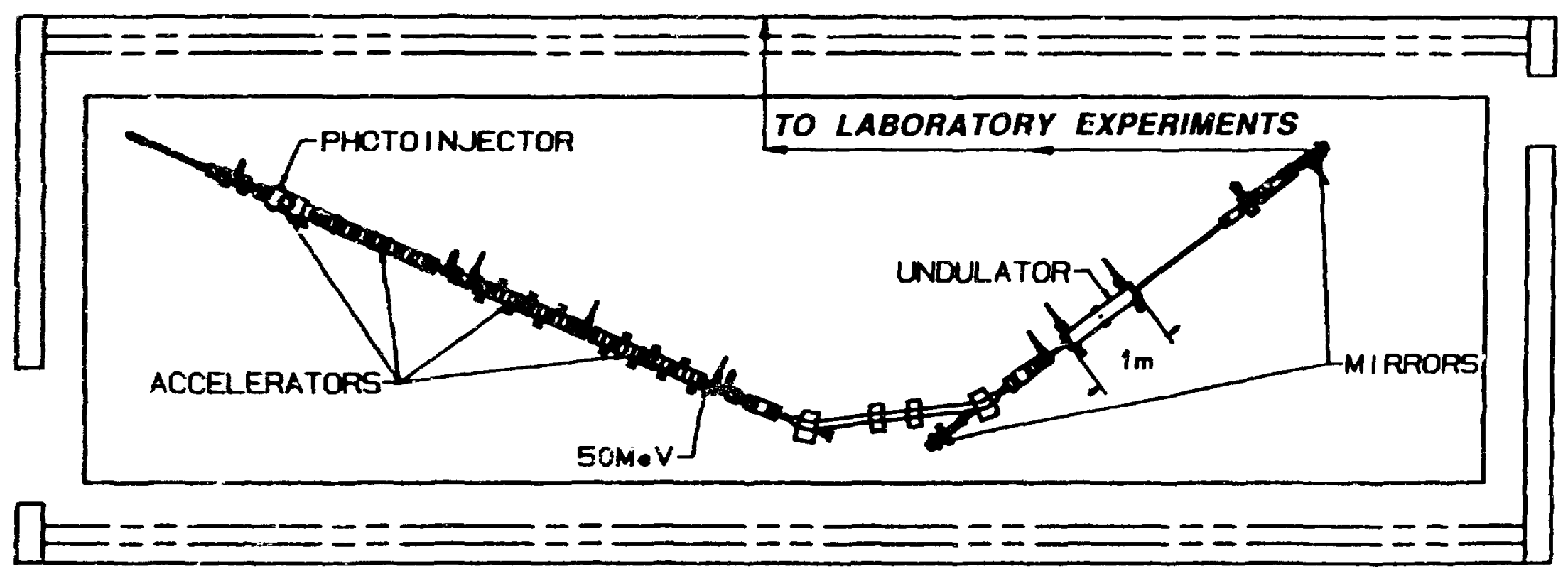




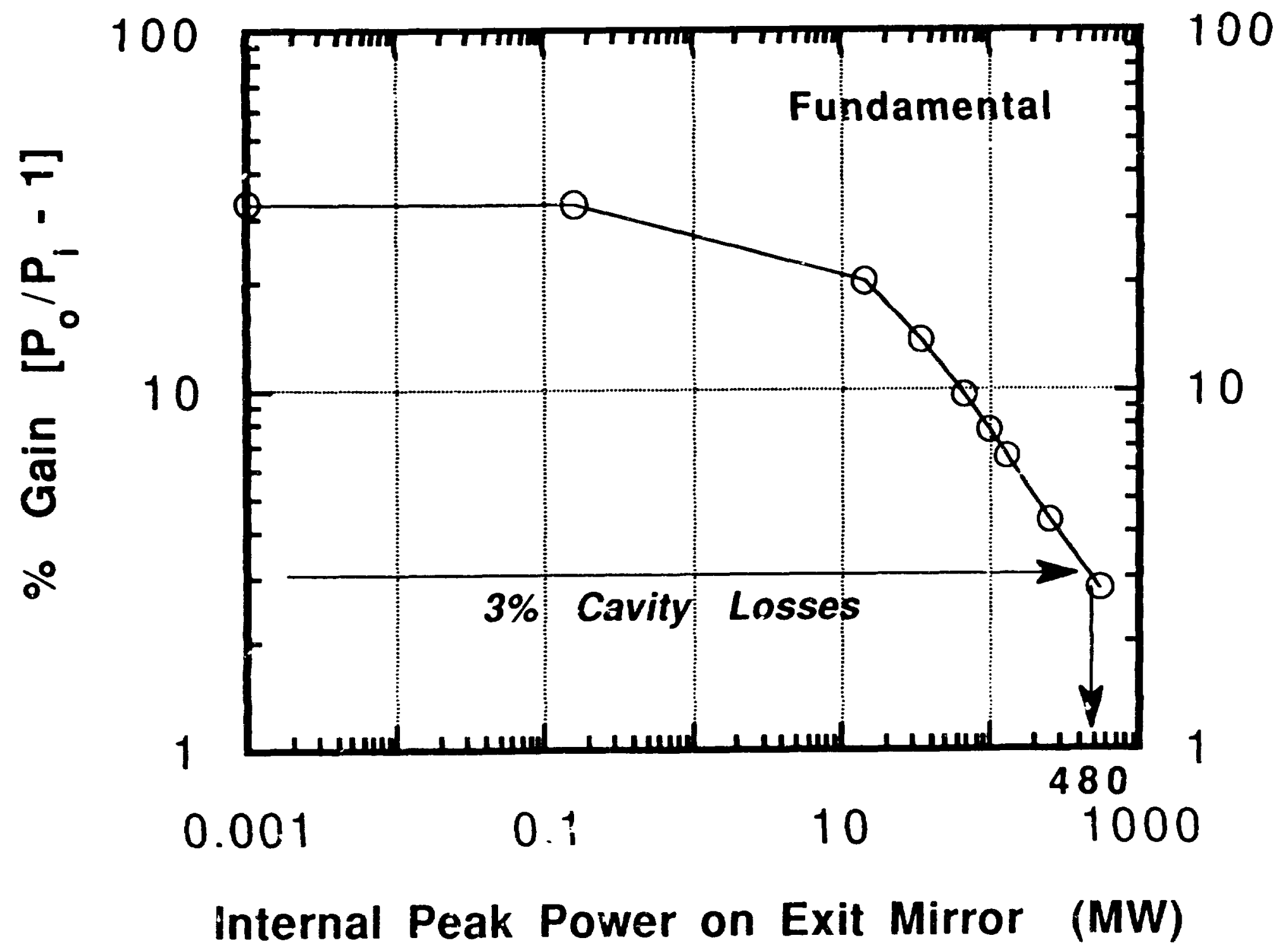




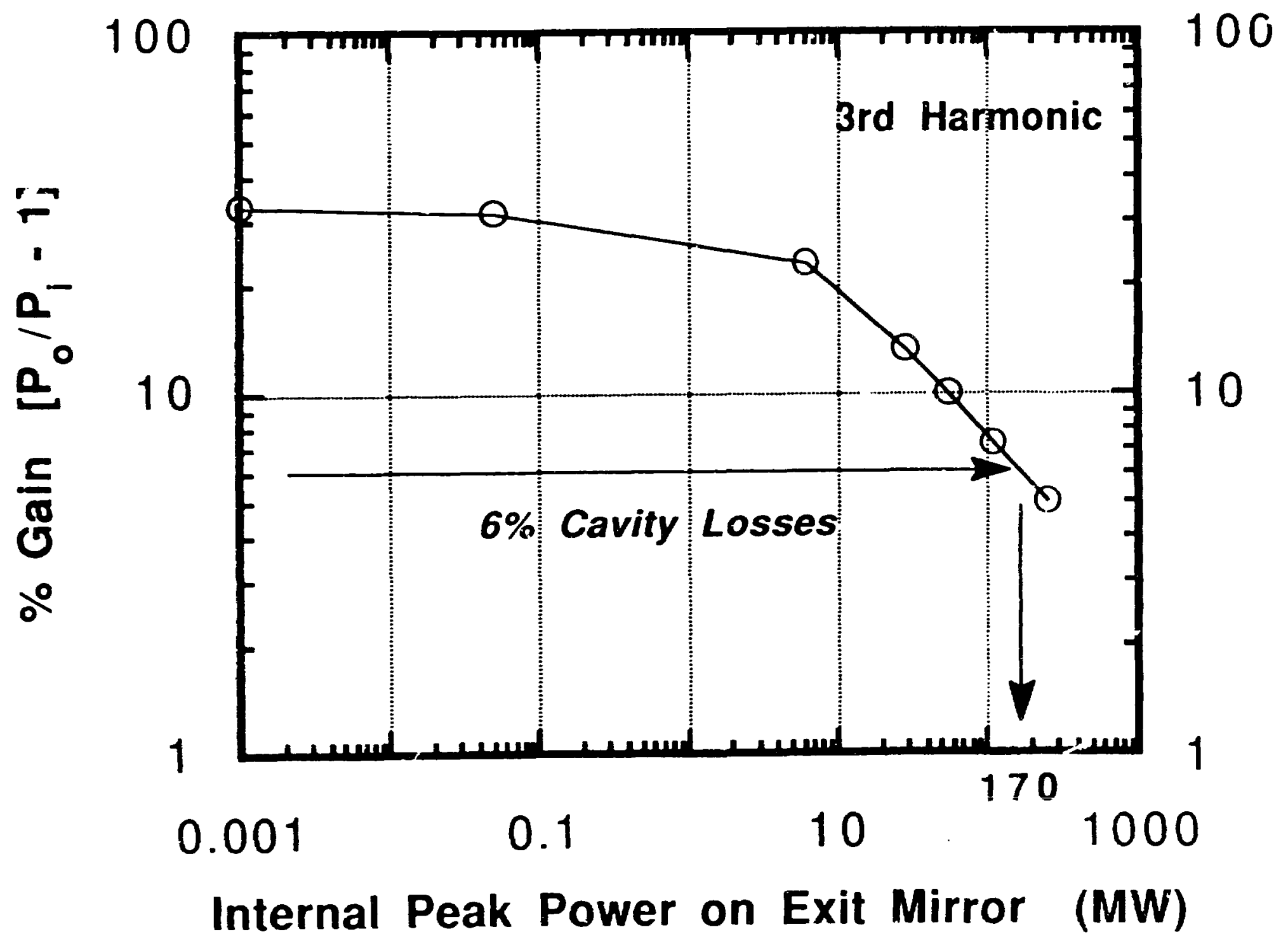




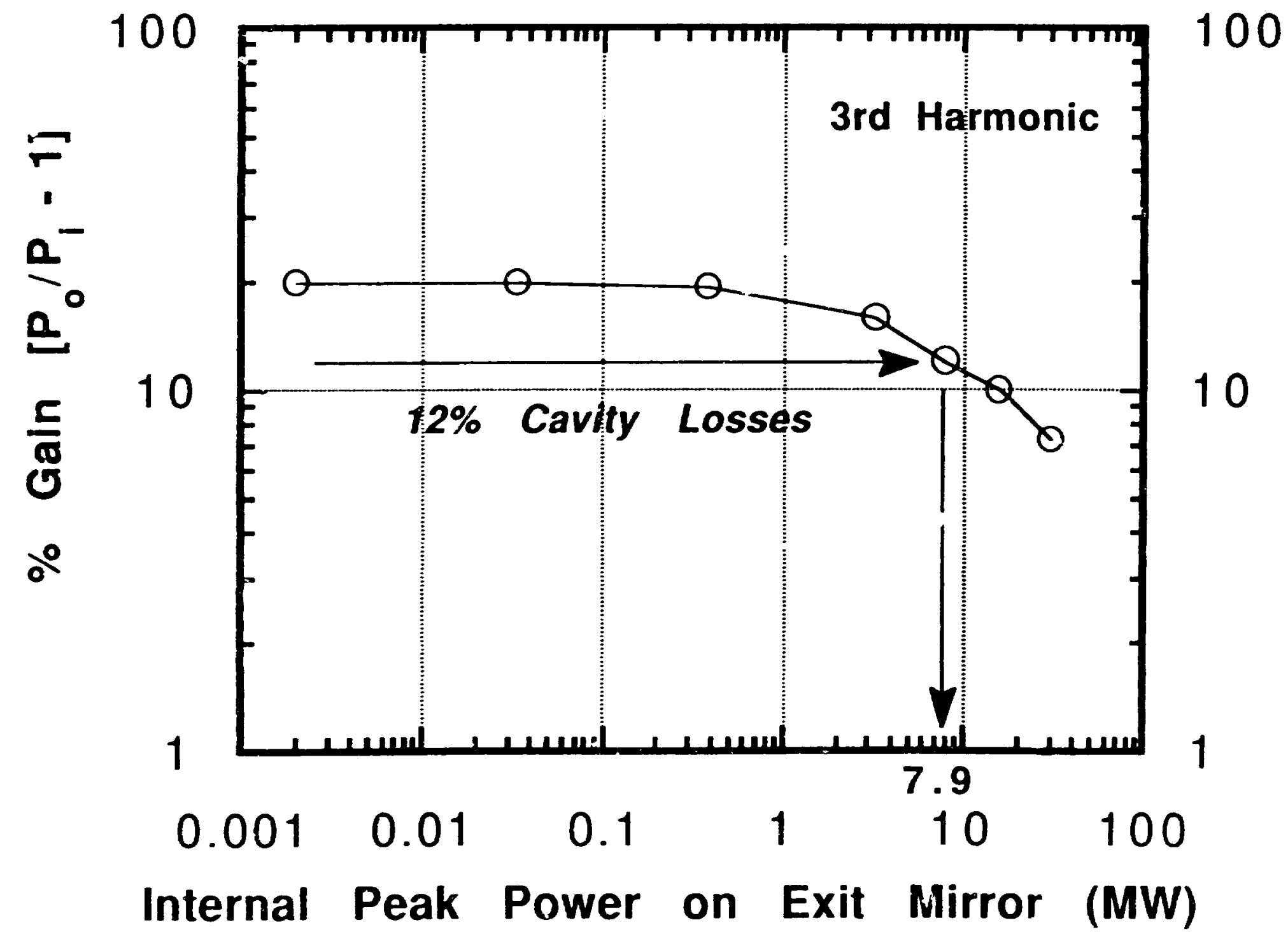

